University of Nebraska - Lincoln

DigitalCommons@University of Nebraska - Lincoln

Faculty Publications: Department of Entomology

Entomology, Department of

1988

\title{
Variation In Chromosome Length Among Five Biotypes of the Greenbug (Homoptera: Aphididae)
}

Z. B. Mayo

Univesity of Nebraska - Lincoln, zmayo1@unl.edu

K. J. Starks

ARS-USDA Plant Science and Water Conservation Laboratory, Stillwater, OK

D. J. Banks

ARS-USDA Plant Science and Water Conservation Laboratory, Stillwater, OK

R. A. Veal

ARS-USDA Plant Science and Water Conservation Laboratory, Stillwater, OK

Follow this and additional works at: https://digitalcommons.unl.edu/entomologyfacpub

Part of the Entomology Commons

Mayo, Z. B.; Starks, K. J.; Banks, D. J.; and Veal, R. A., "Variation In Chromosome Length Among Five Biotypes of the Greenbug (Homoptera: Aphididae)" (1988). Faculty Publications: Department of Entomology. 216.

https://digitalcommons.unl.edu/entomologyfacpub/216

This Article is brought to you for free and open access by the Entomology, Department of at DigitalCommons@University of Nebraska - Lincoln. It has been accepted for inclusion in Faculty Publications: Department of Entomology by an authorized administrator of DigitalCommons@University of Nebraska - Lincoln. 


\title{
Variation in Chromosome Length Among Five Biotypes of the Greenbug (Homoptera: Aphididae)
}

\author{
Z B MAYO, ${ }^{1}$ K. J. STARKS, D. J. BANKS, AND R. A. VEAL \\ Agricultural Research Service, U.S. Department of Agriculture, \\ Plant Science and Water Conservation Laboratory, \\ Stillwater, Oklahoma 74076
}

\begin{abstract}
Ann. Entomol. Soc. Am. 81(1): 128-131 (1988)
ABSTRACT Chromosome-length measurements from five greenbug, Schizaphis graminum (Rondani), biotypes (B, C, E, F, and Maryland) were compared by discriminant analyses procedures. There were highly significant $(P=0.0001)$ differences in total lengths of chromosome sets among biotypes. In individual paired comparisons, where each biotype was compared with only one other biotype at a time, chromosome measurements correctly classified aphids to their respective biotype in $45-85 \%$ of the cases. Degree of correct classification was dependent on the two biotypes being compared and the discriminant function used in the analysis. Results indicate that there are two groups of biotypes that can be correctly distinguished from each other most of the time. Chromosome lengths of biotypes $\mathrm{C}$ and $\mathrm{E}$ were closely related. They could be distinguished from those of biotype $\mathrm{B}$ and $\mathrm{F}$ in $75-85 \%$ of the cases. The Maryland biotype appeared to be more closely related to $\mathrm{C}$ than to the other biotypes. There was considerable variation in the lengths of biotype $\mathrm{C}$ chromosomes, which suggests that biotype $\mathrm{C}$ may comprise several population variants, perhaps separate biotypes. The ranges of variability in length of chromosomes in biotype C overlapped the ranges of biotype $\mathrm{E}$, which suggests that biotype $\mathrm{E}$ may be a selection from biotype $\mathrm{C}$. Conclusions drawn from these data regarding relationships among biotypes are similar to those suggested by biological and plant-damage studies.
\end{abstract}

KEY WORDS Insecta, Schizaphis graminum, discriminant analyses, cytogenetics

THE DEVELOPMENT and use of resistant crop varieties has long been considered an ideal method to reduce damage from aphids such as the greenbug, Schizaphis graminum (Rondani). However, genetic resistance has been short lived in many instances because of the development of new biotypes that were capable of damaging formerly resistant plants. Since 1958 the greenbug has evolved, or there have been discovered, at least five greenbug biotypes.

Classification of greenbug biotypes is usually based on differential reaction to various plant hosts, but some studies have also reported biological and insecticide-susceptibility differences among biotypes (Wood 1961, 1971, Harvey \& Hackerott 1969 , Wood et al. 1969, Wood \& Starks 1972, Teetes et al. 1975, Starks \& Burton 1977, Porter et al. 1982, Kindler et al. 1983, Kindler \& Spomer 1986).

Although many studies have been conducted on various aspects relating to greenbug biotypes, there has been very little work on genetic factors that may be involved in their development. Because of the holocentric nature of aphid chromosomes, chromosome disassociations and rearrangements are very common (Blackman 1979). Blackman (1979) indicated that chromosome aberrations were a

'Dep. of Entomology, University of Nebraska, Lincoln, NE 68583. means of genetic change in aphids. Aphid chromosomes are able to divide normally during mitosis, even after fragmentation by $\mathrm{X}$ rays (Ris 1942). If rearrangements occur that are not immediately detrimental, they may not be selected against until meiotic divisions and recombinations occur during the sexual cycle, assuming that the species has a sexual phase. Blackman (1980) reported that readily visible chromosome rearrangements were apparent among aphids studied in over $50 \%$ of the species that were either completely or partially anholocyclic, but rearrangements were apparent in only $0.3 \%$ of the species with obligate sexual cycles. The greenbug is assumed to be a partially anholocyclic species in North America. However, the importance of the sexual cycle in the various biotypes has not been determined.

The only published research on the cytogenetics of the greenbug was done by Mayo \& Starks (1972), who compared chromosome measurements of thenknown biotypes. Their study showed that chromosome lengths varied significantly among some biotypes. Because of these cytogenetic differences and because new biotypes have continued to develop, more in-depth cytogenetic comparisons among biotypes were warranted. Our objectives were to determine if chromosome differences exist among biotypes and, if they do, whether or not the differences could be used to classify greenbug biotypes.

0013-8746/87/0128-0131\$02.00/0 (C) 1987 Entomological Society of America

This article is a U.S. government work, and is not subject to copyright in the United States. 


\section{Materials and Methods}

Chromosome-length comparisons were made among five greenbug biotypes: B, C, E, F (formerly Ohio), and $M$ (Maryland) ( $M$ has not been officially designated as a biotype, and the symbol is used here for convenience only). Biotypes $\mathrm{B}, \mathrm{C}$, and $\mathrm{E}$ were isolated from field infestations near Stillwater, Okla. The other two are grass-infesting biotypes and were obtained from the ARS-USDA, Field Crops Laboratory, Beltsville, Md. Based on both biological and plant-damage studies involving these and other greenbug population isolates, Kindler \& Spomer (1986) indicated that biotypes B, C, E, and $\mathrm{F}$ exhibited the largest biotypic differences. Biotype $\mathrm{M}$ displayed similarities to biotype $\mathrm{C}$ as well as to $B$ and $F$.

Greenbugs were reared on plants covered with plastic cages in an air-conditioned compartment programmed for ca. $27^{\circ} \mathrm{C}$ and natural light (14-16 $\mathrm{h}$ light). Biotypes $\mathrm{B}, \mathrm{C}$, and $\mathrm{E}$ were reared on 'Wheatland' sorghum, Sorghum bicolor (L.) Moench, and biotypes $\mathrm{F}$ and $\mathrm{M}$ were reared on 'Kentucky' bluegrass, Poa pratensis L.

Chromosome preparations were made by dissecting embryos from a single aphid (selected from 1 of 10-20 culture pots) onto a microscope slide, discarding large embryos, and staining the remaining ones with aceto-orcein based on the method of Sun \& Robinson (1966). The aceto-orcein procedure was selected because it was quick, each slide consisted of the embryos from a single aphid, and there were no confounding problems associated with chemicals such as colchicine and $\mathrm{KCl}$ that would cause excessive condensation of the chromosomes. Hypotonic treatments help spread chromosomes and result in more sets in the same plane of focus. Although this has many advantages, it allows chromosomes in different stages of metaphase to be measured. The absence of hypotonic treatments reduces the number of measurable chromosome sets on each slide. However, most of the chromosomes measured are probably close to their most condensed stage because the longer sets (early metaphase) of chromosomes are seldom on the same plane of focus.

Chromosome measurements were made directly from the slides, under $100 \times$ magnification, with a filar micrometer eyepiece (similar to the method of Mayo \& Starks [1972]). Twenty chromosome sets were measured for each biotype. The selection criterion was that all eight chromosomes in the set be sufficiently distinct to be measured. A maximum of three chromosome sets was measured from each slide (aphid). Because all slides with at least one measurable chromosome set did not contain three measurable sets, 10-12 slides (aphids), depending on the biotype, were needed to obtain the 20 chromosome sets required. The measurement of up to three sets per slide (aphid) provided information on variability of chromosome lengths within an aphid as well as between aphids.
Table 1. Comparison of chromosome lengths within and among greenbug biotypes by discriminant analyses procedures

\begin{tabular}{lccccc}
\hline \hline \multirow{2}{*}{ Chromosome } & \multicolumn{5}{c}{$\begin{array}{c}\text { Avg chromosome length (microns) of } \\
\text { greenbug biotype }\end{array}$} \\
\cline { 2 - 6 } & B & C & E & M & F \\
\hline Homologs & & & & & \\
A & 9.0 & $7.3^{*}$ & 6.5 & 7.7 & 9.8 \\
B & 8.0 & $6.5^{*}$ & 5.8 & 6.8 & 8.3 \\
C & 7.2 & $5.9^{*}$ & 5.4 & 6.2 & 7.5 \\
D & 6.6 & 5.6 & 5.1 & 5.9 & 7.1 \\
E & 6.2 & 5.2 & 4.6 & 5.4 & 6.6 \\
F & 5.5 & 4.6 & 4.2 & 4.8 & $6.0^{*}$ \\
G & 4.3 & $3.5^{*}$ & 3.0 & 3.6 & 4.4 \\
H & $3.7^{*}$ & $3.1^{*}$ & 2.7 & 3.0 & 3.8 \\
Pairs & & & & & \\
A vs B & NS & $*$ & NS & NS & NS \\
C vs D & NS & NS & NS & NS & NS \\
E vs F & $*$ & $*$ & NS & NS & NS \\
G vs H & NS & NS & NS & NS & NS \\
All chromosomes & NS & $*$ & NS & NS & NS \\
\hline
\end{tabular}

${ }^{a}$ Twenty chromosome sets were measured for each biotype.

${ }^{b}$ An asterisk indicates that the variation in length of chromosomes represented by that average or paired comparison was significant at $P=0.05$; NS indicates that the members of the chromosome pair were not significantly different at the above level.

Data for each biotype were analyzed for differences in total set lengths (length of all eight chromosomes) and variations in lengths of individual chromosomes. Discriminant analyses procedures (Lachenbruch \& Goldstein 1979) were used to analyze the total set lengths and individual chromosome-length data.

\section{Results and Discussion}

Discriminant analyses procedures indicated no significant $(P=0.05)$ differences in total chromosome set lengths within aphids (i.e., different chromosome sets from the same aphid). Because chromosomes from the same individual would be expected to be the same length, the lack of withinaphid variation in chromosome lengths provides an indirect indication that variations in the mitotic stage of development was not a significant factor in obtaining consistent chromosome measurements. Further support for this interpretation was provided when additional analyses using all eight chromosomes per set indicated that four of the five biotypes (all except C) had no significant differences in chromosome lengths among aphids within a biotype nor any within-aphid differences (Table 1). A possible explanation for the lack of significant differences among chromosome lengths within and among aphids from the same biotype may relate indirectly to the absence of hypotonic treatments with chemicals such as $\mathrm{KCl}$ during the chromosome staining procedure. These results indicate that this technique reflects relative chromosome lengths rather than differences in mitotic stages of development within each biotype. Therefore, the method is valid for comparing chromosome length 
Table 2. Percentage of the greenbug chromosome sets correctly classified to biotype (paired biotype comparisons) using different discriminant analyses functions

\begin{tabular}{|c|c|c|c|c|}
\hline \multirow{2}{*}{ Biotype } & \multicolumn{4}{|c|}{ Percentage of sets correctly classified to biotype ${ }^{a}$} \\
\hline & $\mathrm{C}$ & $\mathrm{E}$ & F & B \\
\hline \multicolumn{5}{|c|}{ Based on lengths of chromosome $A^{b}$} \\
\hline $\mathbf{E}$ & $60 / 60$ & & & \\
\hline $\mathbf{F}$ & $60 / 80$ & $70 / 85$ & & \\
\hline B & $70 / 80$ & $80 / 80$ & $65 / 45$ & \\
\hline M & $55 / 65$ & $65 / 75$ & $85 / 55$ & $70 / 60$ \\
\hline \multicolumn{5}{|c|}{ Based on total length of chromosome set ${ }^{b}$} \\
\hline $\mathbf{E}$ & $55 / 50$ & & & \\
\hline $\mathbf{F}$ & $65 / 80$ & $70 / 85$ & & \\
\hline B & $70 / 80$ & $85 / 80$ & $65 / 45$ & \\
\hline $\mathbf{M}$ & $50 / 70$ & $65 / 60$ & $85 / 65$ & $70 / 65$ \\
\hline \multicolumn{5}{|c|}{ Based on multi-variance of all chromosomes per set ${ }^{b}$} \\
\hline $\mathrm{E}$ & $65 / 75$ & & & \\
\hline $\mathrm{F}$ & $65 / 80$ & $85 / 80$ & & \\
\hline B & $65 / 80$ & $75 / 75$ & $65 / 60$ & \\
\hline M & $70 / 85$ & $70 / 70$ & $75 / 55$ & $85 / 60$ \\
\hline
\end{tabular}

$a$ The first number of each pair represents the percentage of chromosome sets from the biotype in the left column that could be classified correctly by discriminant analysis functions when compared with the biotype listed in the heading above that number. The second number represents the percentage of correct classifications when the biotype in the heading above the number was compared with the biotype listed in the left column.

${ }^{b}$ The discriminant functions used to conduct the discriminant analyses.

among siblings within a biotype and among biotypes.

Chromosome Lengths. Highly significant $(P=$ $0.0001)$ differences in total chromosome lengths were found among biotypes when all biotypes were analyzed by general linear model procedures. Discriminant analysis of all five biotypes using multivariance procedures indicated that $25-55 \%$, depending on the biotype, of the chromosome sets could be correctly classified to biotype using this procedure. This procedure analyzed the generalized spread distances as a function of the lengths (measured separately) of all eight chromosomes in the genome. Stepwise discriminant analyses indicated that when all biotypes were considered together, total length was the best method for classifying biotypes. Chromosome A (the longest chromosome) was the only one that could be used to distinguish biotypes.

Although chromosome lengths were only moderately successful (25-55\%) in classifying biotypes when all biotypes were considered together, comparing each biotype to only one other biotype at a time was more successful (Table 2). Discriminant analyses involving paired-biotype chromosome data indicated that similar results were obtained regardless of whether total set lengths, only chromosome A of each set, or the generalized spread distance as a function of the lengths of all eight chromosomes were used in the analyses (Table 2). The last method was slightly better than the first two. In biotype-paired comparisons, chromosome measurements correctly classified aphids to their
Table 3. Probability of significant differences between greenbug biotypes using the length of chromosome $A$ in analysis of variance tests on all possible paired combinations of biotypes

\begin{tabular}{|c|c|c|c|c|}
\hline \multirow{2}{*}{$\begin{array}{l}\text { Bio- } \\
\text { type }\end{array}$} & \multicolumn{4}{|c|}{ Probability of significant $F$ value for biotype } \\
\hline & $\mathbf{E}$ & $\mathbf{F}$ & $\mathrm{B}$ & $\mathbf{M}$ \\
\hline $\mathrm{C}$ & 0.2372 & 0.0034 & 0.0160 & 0.4853 \\
\hline $\mathbf{E}$ & & 0.0001 & 0.0003 & 0.0246 \\
\hline F & & & 0.2221 & 0.0023 \\
\hline B & & & & 0.0157 \\
\hline
\end{tabular}

respective biotype $45-85 \%$ of the time. Further breakdown of the data indicated that biotypes $\mathrm{C}$ and $\mathrm{E}$ can be distinguished from biotypes $\mathrm{B}, \mathrm{F}$, and $\mathrm{M} 60-85 \%$ of the time and from $\mathrm{B}$ and $\mathrm{F} 75-$ $85 \%$ of the time, depending on the biotypes involved and the discriminant functions used in the analysis.

Using the lengths of chromosome A, analysis-ofvariance tests on all possible paired combinations of biotypes indicated that biotypes $\mathrm{C}$ and $\mathrm{E}$ were not significantly different from each other, but they were different (shorter) than biotypes $\mathrm{B}$ and $\mathrm{F}(\mathrm{Ta}$ ble 3). Chromosome lengths of biotypes $\mathrm{B}$ and $\mathrm{F}$ were not significantly different from each other. Biotype $\mathrm{M}$ differed significantly from all biotypes except $\mathrm{C}$.

Based on chromosome-length comparisons, the data suggest that biotypes $\mathrm{C}$ and $\mathrm{E}$ are closely related and biotypes $\mathrm{B}$ and $\mathrm{F}$ are closely related. Biotype $\mathrm{M}$ appears to be somewhere between the two groupings, but it is probably more closely related to $\mathrm{C}$ than to the other biotypes. This assumption is basically the same as presented by Kindler \& Spomer (1986) from their biological and plant-damage studies. However, an important difference is that biotype $F$ readily produces sexual morphs, whereas B does not (Mayo, unpublished).

There were considerable and significant ranges in the lengths of chromosomes within biotype $\mathrm{C}$ (Table 1). Discriminant analyses indicate that the range in lengths of biotype $\mathrm{C}$ chromosomes overlaps the ranges of those for biotype $\mathrm{E}$. This indicates a considerable amount of variability within biotype $\mathrm{C}$, which suggests the possibility that biotype C may comprise several population variants, possibly biotypes, and that biotype $\mathrm{E}$ may be a selection from biotype $\mathrm{C}$. This explanation is tenable because biotypes $\mathrm{C}$ and $\mathrm{E}$ are biologically similar in many ways.

These data indicate some consistent differences in chromosome lengths among biotypes. However, the data do not provide information regarding the reasons for the differences in lengths. The differences may be due to actual differences in the size of the chromosomes because of factors such as duplications or deletions, or they may be due to biological factors that result in the measurement of chromosomes from cells that are in slightly different stages of development for each biotype. The first reason appears to be the more likely expla- 
nation, because the chromosome differences reflect virtually the same relations among biotypes as biological and plant-damage studies suggest. However, if the second possibility is true, it is a consistent difference for the biotypes studied. Regardless of the reasons for the differences in chromosome lengths, this procedure provides a tool for further study and comparison of aphid biotypes. The results also provide some insight into possible genetic mechanisms that may be involved in biotype development.

\section{Acknowledgment}

We thank R. H. Ratcliffe, Agricultural Research Service, U.S. Department of Agriculture, Field Crops Laboratory, Beltsville, Md., for supplying some of the cultures of the greenbug, and T. Popham, ARS-USDA biometrician at Stillwater, Okla., for his capable assistance with the statistical analyses. This article is Paper No. 8190, Journal Series, Nebraska Agric. Exp. Stn., and Contribution No. 629 of the Department of Entomology, University of Nebraska-Lincoln.

\section{References Cited}

Blackman, R. L. 1979. Stability and variation in aphid clonal lineages. Biol. J. Linn. Soc. 11: 259-277.

1980. Chromosome numbers in the Aphididae and their taxonomic significance. Syst. Entomol. 5: 7-25.

Harvey, T. L. \& H. L. Hackerott. 1969. Recognition of a greenbug biotype injurious to sorghum. J. Econ. Entomol. 62: 776-779.

Kindler, S. D. \& S. M. Spomer. 1986. Biotypic status of six greenbug (Homoptera: Aphididae) isolates. Environ. Entomol. 15: 567-572.

Kindler, S. D., R. Staples, S. M. Spomer \& O. Adenij i. 1983. Resistance of bluegrass cultivars to biotypes
$\mathrm{C}$ and $\mathrm{E}$ greenbug (Homoptera: Aphididae). J. Econ. Entomol. 76: 1103-1105.

Lachenbruch, P. A. \& M. Goldstein. 1979. Discriminant analysis. Biometrics 35: 69-86.

Mayo, Z B, Jr., \& K. J. Starks. 1972. Sexuality of the greenbug, Schizaphis graminum, in Oklahoma. Ann Entomol. Soc. Am. 65: 671-675.

Porter, K. B., G. L. Peterson \& O. Vise. 1982. A new greenbug biotype. Crop Sci. 22: 847-850.

Ris, H. 1942. A cytological and experimental analysis of the miotic behavior of the univalent X-chromosome in the bearberry aphid Tamalia (Phyllaphis) coweni (Ckll). J. Exp. Zool. 90: 267-330.

Starks, K. J. \& R. L. Burton. 1977. Greenbugs: determining biotypes, culturing, and screening for plant resistance, with notes on rearing parasitoids. U.S. Dep. Agric. Tech. Bull. 1556.

Sun, R. \& A. G. Robinson. 1966. Chromosome studies on 50 species of aphids. Can. J. Zool. 44: 649-653.

Teetes, G. L., C. A. Schaefer, J. R. Gipson, R. C. McIntyre \& E. E. Latham. 1975. Greenbug resistance to organophosphorous insecticides on the Texas High Plains. J. Econ. Entomol. 68: 214-216.

Wood, E. A., Jr. 1961. Biological studies of a new greenbug biotype. J. Econ. Entomol. 54: 1171-1173.

1971. Designation and reaction of three biotypes of the greenbug cultured on resistant and susceptible species of sorghum. J. Econ. Entomol. 64: 183-185.

Wood, E. A., Jr., \& K. J. Starks. 1972. Effect of temperature and host plant interaction on the biology of three biotypes of the greenbug. Environ. Entomol. 1: 230-234.

Wood, E. A., Jr., H. L. Chada \& P. N. Saxena. 1969. Reaction of small grains and grain sorghum to three greenbug biotypes. Okla. Agric. Exp. Stn. Prog. Rep. P-618.

Received for publication 14 October 1986; accepted 3 August 1987. 